\title{
Understanding of Various Configurations of Ejector Cycles Applied for Refrigeration
}

\author{
Sunjae Kim ${ }^{1}$, Yongseok Jeon ${ }^{1}$, Yongchan Kim ${ }^{2 *}$ \\ ${ }^{1}$ Mechanical Engineering Department, Korea University \\ Seoul 136-717, Seoul, Korea \\ 730sun@korea.ac.kr; silverriver@korea.ac.kr \\ $2^{2}$ Department of Mechanical Engineering, Korea University \\ Seoul 136-717, Seoul, Korea \\ yongckim@korea.ac.kr
}

\section{Extended Abstract}

Globally, energy crisis has been a controversial issue for decades. Each government is trying its best to satisfy their nation's energy demand. To save energy and not to waste energy, many different methods are being suggested. Developing energy efficient machineries is one of the possible methods to reduce power consumption and save energy. The ejector cycle is an energy efficient refrigeration cycle compared to conventional vapor compression cycles in that it can recover expansion loss by replacing conventional expansion devices with an ejector. Expansion devices such as capillary or electrical expansion valve (EEV) suffer from expansion loss due to isenthalpic expansion. However the ejector can overcome such defect by conducting isentropic expansion process. Various kinds of ejector cycles were suggested in the open literatures. This study aims to compare and estimate Two Phase Ejector (TPE) cycle and Condenser Outlet Split (COS) cycle. Each cycle will be estimated by comparing the trends of system parameters such as pressure lifting ratio, mass flow rate, cooling capacity, power consumption, and COP. Also each ejector cycle has its own pros and cons which should be considered when it is being applied on specific refrigeration systems. The TPE cycle which is appropriate for heat pump application due to ability of simple pipe alignment can suffer from separator inefficiency since it contains a separator as its component. In contrast, the COS cycle which does not use a separator in the cycle never suffers from such problem. Also the COS cycle has two evaporators which operate in different temperature ranges. This can allow the cycle to better match the temperature gliding of a single stream of fluid or the cycle can be applied on a parallel cycle which needs two different evaporators such as a refrigerator. In addition, the COS cycle is less sensitive to operation condition and ejector design due to its unique cycle configuration. Due to these mentioned different characteristics of each cycle, it should be carefully selected for applying the cycles to products. To estimate each cycle's application ability, the TPE cycle was mounted on a heat pump system while COS cycle was mounted on a refrigerator system. Each system showed $10.2 \%$ and $10.5 \%$ of COP improvement, respectively. COP improvement was calculated by comparing each system's COP to each system's baseline cycle COP.

\section{References}

[1] G. Pottker, P. Hrnjak, "Ejector in R410A vapor compression systems with experimental quantification of two major mechanisms of performance improvement: Work recovery and liquid feeding," International Journal of Refrigeration, vol. 50, pp. 184-192, 2015.

[2] N. Lawrence, S. Elbel, "Theoretical and practical comparison of two-phase ejector refrigeration cycles including First and Second Law analysis," International Journal of Refrigeration, vol. 30, pp. 1220-1232, 2013. 